\title{
Development of Colloidal Gold- Based Immunochromatographic Assay for Rapid Detection of Goose Parvovirus
}

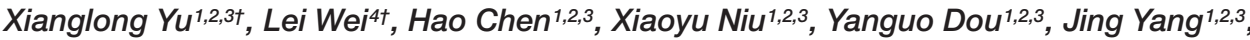 \\ Zhenzhong Wang ${ }^{1,2,3}$, Yi Tang ${ }^{1,2,3 *}$ and Youxiang Diao ${ }^{1,2,3 *}$ \\ 'College of Animal Science and Technology, Shandong Agricultural University, Tai'an, China, ${ }^{2}$ Shandong Provincial Key \\ Laboratory of Animal Biotechnology and Disease Control and Prevention, Tai'an, China, ${ }^{3}$ Shandong Provincial Engineering \\ Technology Research Center of Animal Disease Control and Prevention, Tai'an, China, ${ }^{4}$ Tai'an City Central Hospital, Tai'an, \\ China
}

OPEN ACCESS

Edited by:

Akio Adachi,

Kansai Medical University, Japan

Reviewed by:

Sven M. Bergmann,

Friedrich Loeffler Institute, Germany

Sergio Adrian Guerrero,

National Technological University,

Argentina

${ }^{*}$ Correspondence:

Yi Tang

tyck288@163.com

Youxiang Diao

yxdiao@126.com

tThese authors have contributed equally to this work

Specialty section: This article was submitted to

Virology,

a section of the journa

Frontiers in Microbiology

Received: 27 December 2017

Accepted: 24 April 2018

Published: 14 May 2018

Citation:

Yu X, Wei L, Chen H, Niu X, Dou Y,

Yang J, Wang $Z$, Tang $Y$ and Diao $Y$

(2018) Development of Colloidal Gold-

Based Immunochromatographic

Assay for Rapid Detection of Goose

Parvovirus. Front. Microbiol. 9:953.

doi: 10.3389/fmicb.2018.00953
Goose parvovirus (GPV) remains as a worldwide problem in goose industry. For this reason, it is necessary to develop a new diagnostic approach that is easier and faster than conventional tests. A rapid immunochromatographic assay based on antibody colloidal gold nanoparticles specific to GPV was developed for the detection of GPV in goose allantoic fluid and supernatant of tissue homogenate. The monoclonal antibodies (Mab) was produced by immunizing the BALB/c mice with purified GPV suspension, and the polyclonal antibody $(\mathrm{pAb})$ was produced by immunizing the rabbits with recombinant VP3 protein. The colloidal gold was prepared by the reduction of gold salt with sodium citrate coupled with Mab against GPV. The optimal concentrations of the coating antibody and capture antibody were determined to be $1.6 \mathrm{mg} / \mathrm{ml}$ and $9 \mu \mathrm{g} / \mathrm{ml}$. With visual observation, the lower limit was found to be around $1.2 \mu \mathrm{g} / \mathrm{ml}$. Common diseases of goose were tested to evaluate the specificity of the immune colloidal gold (ICG) strip, and no cross-reaction was observed. The clinical detection was examined by carrying out the ICG strip test with 92 samples and comparing the results of these tests with those obtained via agar diffusion test and polymerase chain reaction (PCR) test. Therefore, the ICG strip test was a sufficiently sensitive and accurate detection method for a rapid screening of GPV.

Keywords: goose parvovirus, colloidal gold, immunochromatographic strip, monoclonal antibody, rapid detection

\section{INTRODUCTION}

Goose parvovirus (GPV) are small, non-enveloped, single-stranded DNA viruses, which have been classified in the family parvoviridae, genus parvovirus. The GPV particles can be observed in hexagonal or circular appearance with a diameter of 20-24 nm through scanning electron microscope. Three kinds of structural proteins (VP1, VP2, VP3) present in the virus, wherein VP3 protein is the major structural protein (Shao et al., 2014). This virus was first detected by Fang (1962) in China. In the following years, GPV was reported in Europe. GPV infection is caused by GPV, which is an acute or subacute sepsis in 4-20 days old goslings characterized by high infectiousness and exudative inflammatory bowel disease. This disease spreads rapidly and has a 
high fatality rate, and the mortality rate of goslings within 5 days old is above 95\%. The transmission and prevalence of GPV infection has caused severe economic losses and restricted the development of goose industry.

The current methods for diagnosing GPV infections are routine molecular assays such as polymerase chain reaction (PCR) test (Limn et al., 1996), fluorescent quantitative real-time PCR test (Yang et al., 2009), agar diffusion test and LoopMediated isothermal amplification (Yang et al., 2010). Indirect ELISA based on VP3 proteins are commonly used to detect GPV antibodies (Zhang et al., 2010). All of these are effective and accurate methods of detecting viral infections, however, these methods are time consuming and instrument required, and can only be carried out in laboratories by professional. Therefore, development of a rapid detection method to monitor GPV would be desirable.

The one-step immunochromatographic assay using gold nanoparticles has been widely used in certain fields (Meng et al., 2014). This method is rapid and convenient to use and requires few equipment. However, there is no report about the detection of GPV using the one-step immunochromatographic assay. So, the aim of this study was to establish a colloidal gold-based immunochromatographic assay for the rapid detection of GPV, to control the spread and epidemic of the disease, and to promote the development of goose industry.

\section{MATERIALS AND METHODS}

\section{Ethics Statement}

All applicable international, national, and institutional guidelines for the care and use of animals were followed to minimize suffering. Animal procedures was approved by the Committee on the Ethics of Animal of Shandong (permit number: 201750017). Two young adult (35-day-old) BALB/c mice were used in the immunization protocols and maintained at Shandong Agricultural University with water and food ad libitum, relative humidity $40-60 \%$ conditions and a $12-12$ h light-dark cycle. Mice were euthanized using rapid cervical dislocation.

\section{Materials and Reagents}

Goose parvovirus, avian influenza virus (H5, H7, H9), duck hepatitis virus, tembusu virus, fowl adenovirus, goose reovirus and muscovy duck parvovirus were isolated and maintained in our laboratory. The purified GPV was isolated from the GPVpositive allantoic fluid by sucrose density gradient centrifugation in our laboratory. Recombinant VP3 protein was expressed by prokaryotic expression system in the previous work and VP3 concentration was determined to be $3.34 \mathrm{mg} / \mathrm{ml}$ by the BCA Protein Assay Kit. Goat anti-mouse IgG antibody and bovine serum albumin (BSA) were purchased from Boster Biological Technology Co., Ltd (Wuhan, China). Nitrocellulose (NC) membrane, absorbent pad, sample pad, conjugate pad, and PVC sheets were obtained from Millipore (Shanghai, China). Hydrogen tetra-chloroaurate hydrate (HAuCl4) and trisodium citrate were obtained from Shanghai Chemical Reagents (Shanghai, China). Phosphate buffer saline (PBS,
$\mathrm{pH} 7.4,0.01 \mathrm{M}$ in $0.85 \% \mathrm{NaCl}$ ) was prepared in our lab. BALB/c mice were purchased from Spfanimals, Inc. (Beijing, China). All other chemicals in the present study were either chemical pure or with highest quality.

\section{Preparation of Monoclonal Antibodies}

Monoclonal antibodies against GPV (anti-GPV Mab) were prepared as described by Yin et al. (2010) with some modifications. Briefly, purified GPV suspension was verified by PCR test and analyzed by SDS-PAGE, then emulsified with Freund's adjuvant in a 1:1 ratio and $\mathrm{BALB} / \mathrm{c}$ mice were immunized with the fluid at the volume of $0.2 \mathrm{ml}$. Hybridomas were generated by the fusion of spleen cells to SP2/0 myeloma cells. The reactivity and specificity of hybridoma cells to GPV were tested by Indirect ELISA. For Indirect ELISA, $2 \mu \mathrm{g} / \mathrm{ml}$ purified GPV in carbonate buffer solution was incubated in black Maxisorb 96-well plates overnight at $4^{\circ} \mathrm{C}$ and the plates were blocked by $5 \%$ non-fat dry milk for $2 \mathrm{~h}$ at $37^{\circ} \mathrm{C}$, then supernatant of hybridoma was then added at $100 \mu \mathrm{L} /$ well. Anti-GPV Mab was selected through three successive limiting dilutions, and supernatants of hybridoma showing strong reactivity against GPV were used for mass production of Mabs. Ascites containing abundant Mabs were obtained from big female BALB/c mice, and purified by affinity chromatography (Shukla and Thommes, 2010). The concentration of the Mabs was determined with the DeNovix microvolume spectrophotometer (DeNovix, Inc., DS-11, United States), and used as a reference for optimal concentration of the coating antibody.

\section{Preparation of Polyclonal Antibody}

Polyclonal antiserum against GPV were prepared according to a previously published report with slight modifications (Ma et al., 2017). It was generated in rabbits by immunizing the animals with recombinant VP3 protein and used as a coating reagent fixed on NC membrane (test line). Specific steps are as follows: VP3 protein was blended and emulsified with the same volume of FCA or FIA, then two healthy rabbits were injected into the back by multiple sites subcutaneous injection with the $200 \mu \mathrm{g}$ VP3 protein. The entire immunization procedure comprised four injections, wherein the first immunization was with FCA, later with FIA. The first two injections were carried out at an interval of 2 weeks, and the subsequent two injections were carried out at intervals of 1 week. The polyclonal antibody was purified from the serum by sequential precipitation with caprylic acid and ammonium sulfate. Indirect ELISA was performed to measure the antibody titers of negative serum, unpurified serum and purified serum. The concentration of the antibodies was determined with Bradford method.

The pAb was diluted with PBS (0.01 M, pH 7.4) into gradient concentration $(0.2 \mathrm{mg} / \mathrm{ml}, 0.4 \mathrm{mg} / \mathrm{ml}, 0.8 \mathrm{mg} / \mathrm{ml}, 1.6 \mathrm{mg} / \mathrm{ml}$, $3.2 \mathrm{mg} / \mathrm{ml}$ ), then fixed to the NC membrane with ZX1000 Dispense Platform (BioDot Inc., United States), and goat antirabbit antibody (Control line) was fixed simultaneously. The blank control and positive samples containing GPV were tested to determine the optimal concentrations of the coating antibody. 


\section{Synthesis of Colloidal Gold}

All glassware used, including beakers and flasks, was washed with ultrapure water, pretreated in aqua regia, then washed in ultrapure water and dried before use. Colloidal gold nanoparticles with a mean particle diameter of $20 \mathrm{~nm}$ were produced by reduction of gold chloride with $1 \%$ sodium citrate according to a previously described method (Zhang et al., 2015). Briefly, the ultrapure water $(100 \mathrm{ml})$ was heated with electric heating to boiling point in an Erlenmeyer flask with a magnetic stirrer, and then $1 \mathrm{ml}$ of the $1 \%$ the chloroauric acid solution were added to the flask rapidly, then $3.0 \mathrm{ml}$ of $1 \%$ sodium citrate solution was added quickly into the solution under stirring. When the color of the solution changed from blue to dark red, the solution was boiled for another $10 \mathrm{~min}$, then stopped heating, stirred for $15 \mathrm{~min}$, then cooled and stored at $4^{\circ} \mathrm{C}$ with $0.05 \%$ sodium azide.

\section{Preparation of the Colloidal Gold-Mab Conjugate}

The optimal amount of the Mab concentration for conjugation with the colloidal gold solution was determined at first (Liu et al., 2012). Briefly, the Mab was diluted with PBS (0.015 M, pH 7.4) into different concentration $(0 \mu \mathrm{g} / \mathrm{ml}, 5 \mu \mathrm{g} / \mathrm{ml}, 7.5 \mu \mathrm{g} / \mathrm{ml}, 10$ $\mu \mathrm{g} / \mathrm{ml}, 20 \mu \mathrm{g} / \mathrm{ml}, 30 \mu \mathrm{g} / \mathrm{ml}, 50 \mu \mathrm{g} / \mathrm{ml})$ and $20 \mu \mathrm{l}$ solution of each concentration was added into $1 \mathrm{ml}$ of colloidal gold solution (pH 8.5), with slight shaking for $10 \mathrm{~min}$. Then $100 \mu \mathrm{l} 10 \% \mathrm{NaCl}$ was added into each tube and stirred for another $10 \mathrm{~min}$. The mixtures were incubated for $1 \mathrm{~h}$ at room temperature and then observed. The color of the reaction changed from bright red to blue as the concentration of Mab decreases, and the optimum concentration of Mab for colloidal gold labeling is the minimum concentration of red invariant. Colloidal gold solution without $\mathrm{NaCl}$ was used as a negative control. Typically, the working concentration in the assay is $20 \%$ higher than the optimum concentration.

The colloidal gold probe was prepared according to the procedure in the literature with slight modification ( $\mathrm{Ju}$ et al., 2010). The $\mathrm{pH}$ of the colloidal gold was adjusted to 8.5 by dropwise addition of $0.1 \mathrm{~mol} / \mathrm{L} \mathrm{K}_{2} \mathrm{CO}_{3}$. The $\mathrm{Mab}$ was diluted to $20 \mu \mathrm{l}$ with PBS to the optimum concentration of Mab for colloidal gold labeling and added to $1 \mathrm{ml} \mathrm{pH}$-adjusted colloidal gold solution, with stirring at intervals for $30 \mathrm{~min}$. Then 20 $\mu \mathrm{l}$ of $10 \% \mathrm{BSA}$ solution were added to the mixture to block the un-reacted sites of the gold nanoparticles, with stirring at intervals for $20 \mathrm{~min}$, and then centrifuged at 12,000 rpm for $10 \mathrm{~min}$. After centrifugation and removal of the supernatant, the precipitate was re-suspended in $100 \mu$ l dilution buffer [0.002 $\mathrm{mol} / \mathrm{L}$ sodium carbonate solution ( $\mathrm{pH} 8.5$ ) containing $1 \% \mathrm{BSA}$ and $0.2 \%$ sodium azide] and stored at $4^{\circ} \mathrm{C}$ for further use.

\section{Preparation of the Immunochromatographic Strip}

The colloidal gold probe was added dropwise to the conjugate pad and dried under the fan for $2 \mathrm{~h}$. Goat-anti-rabbit antibody and rabbit anti-GPV polyclonal antibody were fixed on a NC membrane at two discrete zones, with a volume of $1 \mu \mathrm{l} / \mathrm{cm}^{2}$ to form the test $(\mathrm{T})$ line and control $(\mathrm{C})$ line, respectively, with the Biodot equipment (BioDot, Inc., ZX 1000, United States).

The immunochromatographic strip consists five components (Liu et al., 2016): NC membrane, absorbent pad, sample pad, conjugate pad, and PVC sheets. The PVC sheet was used as the bottom of the test strip, the NC membrane pad was attached to the middle of the PVC sheet, the conjugate pad was attached to the edge of the membrane with 1-2 mm overlap, and then the sample pad was attached to the edge of the conjugate pad in a similar manner. The absorbent pad was attached to the top

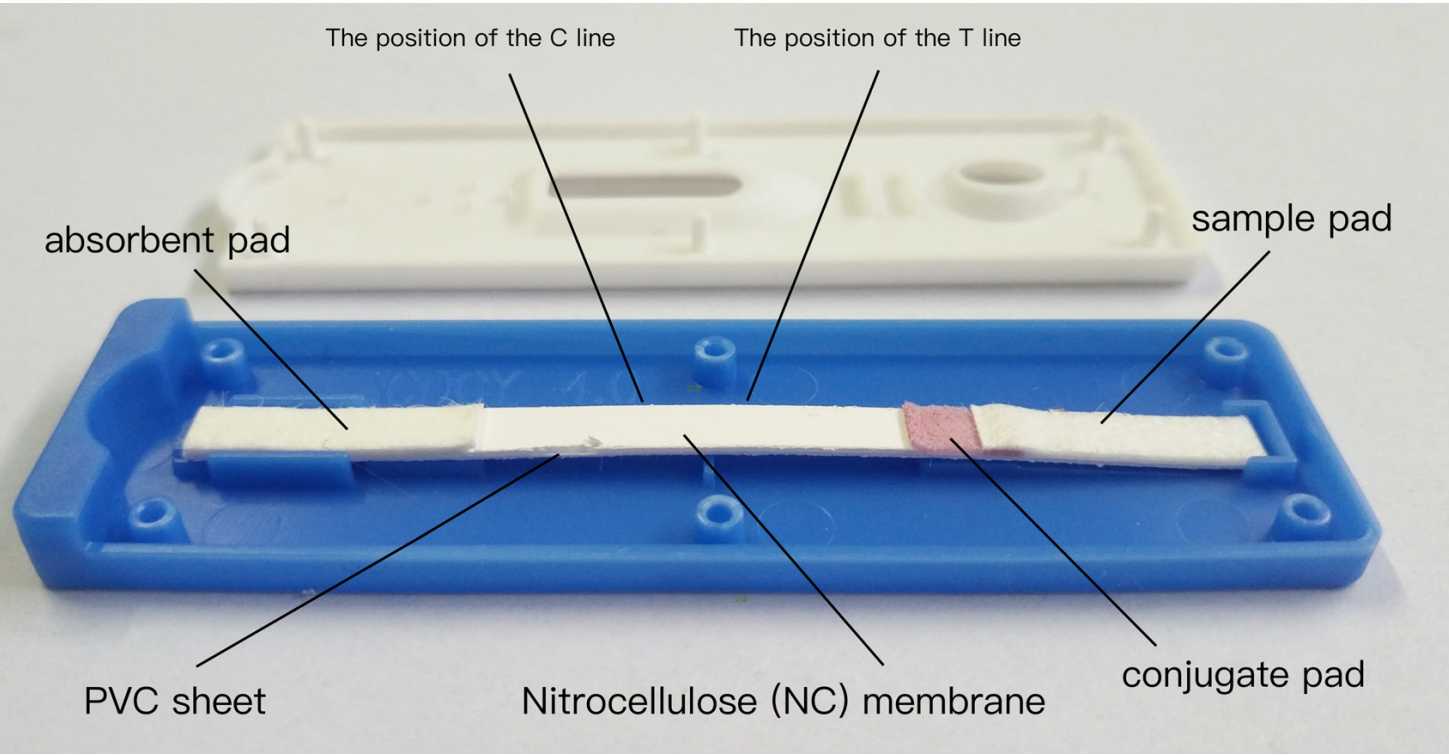

FIGURE 1 | Schematic diagram of test strip. 
of the membrane with 1-2 mm overlap. The sheet was cut into cut into $4 \mathrm{~mm}$-wide strips with a strip-cutter (model CM4000, BioDot, Irvine, CA, United States), and then sealed in a plastic backing plate. The schematic diagram of the test strip is shown in Figure 1. These strips were stored dried at $4^{\circ} \mathrm{C}$ for further use.

In order to ensure the accuracy and effectiveness of the immune colloidal gold (ICG) strip developed in this assay, we carried the ICG assay with a panel of control biological samples containing a GPV-positive and a GPV-negative control. The result also can be used as a reference when other samples carried by ICG assay.

\section{Assay Principle}

This assay was based on the immunochromatography and initially developed for determination of pregnancy on spot (Paek et al., 2000). Specific contents are as follows: Two antibodies binding distinct epitopes present on the virus molecule are used. One (coating antibody) labeled with a colloidal gold nanoparticles and the other (capture antibody) fixed onto surfaces of NC membrane. The coating antibody is in a dehydrated state within the conjugate pad. When standard solution or sample were added onto the sample pad of the test strip, the binder can be instantaneously dissolved upon contact with an aqueous medium containing virus. Then the antibody formed a complex with the virus in the liquid phase and moved forward continuously until it was captured by the antibody fixed on the surfaces of NC membrane, which generated a signal in proportion about the virus concentration. Furthermore, an additional antibody specific to the coating antibody can be used to produce a control signal. The absorbent pad is located at the top to induce by capillarity that enables the immune complex to be pulled to the fixed antibody. A visible color appeared in less than $10 \mathrm{~min}$, and the intensity determines the amount of the virus. In other word, the more virus that was present in the sample, the more noticeable the red band appeared.

\section{Sensitivity, Specificity, and Stability of the Immunochromatographic Strip}

The purified GPV suspension which concentrated in the previous work was diluted to different concentrations $(1.2 \mathrm{mg} / \mathrm{ml}, 120$ $\mu \mathrm{g} / \mathrm{ml}, 12 \mu \mathrm{g} / \mathrm{ml}, 1.2 \mu \mathrm{g} / \mathrm{ml}, 120 \mathrm{ng} / \mathrm{ml}, 12 \mathrm{ng} / \mathrm{ml}$ and $1.2 \mathrm{ng} / \mathrm{ml})$, and PBS (pH 7.4) was used as negative control. ICG strip test, agar diffusion test and PCR test were carried out, respectively, with different concentration solutions, to compare and evaluate the sensitivity of the immunochromatographic strip (Liu et al., 2017).

Common viruses of goose were tested to evaluate the specificity of the immunochromatographic strip, including GPV, avian influenza virus ( $\mathrm{H} 5, \mathrm{H} 7, \mathrm{H} 9)$, duck hepatitis virus, tembusu virus, fowl adenovirus, goose reovirus and muscovy duck parvovirus. PBS ( $\mathrm{pH} 7.4$ ) was used as negative control.

All immunochromatographic strips were stored for 8 months at room temperature $\left(25^{\circ} \mathrm{C}\right)$ and at $4^{\circ} \mathrm{C}$, respectively, to evaluate the stability of the strips during storage (Liu et al., 2017). The sample contaminated by GPV was used as a positive control and PBS (pH 7.4) was used as a negative control.

\section{Detection of Clinical Samples}

A total of 92 suspected samples were used in this study, and clinically determined symptoms including diarrhea and intestinal embolism can be detected. All samples were collected as part of routine veterinary procedures containing goose allantoic fluid and supernatant of tissue homogenate, and they were examined using the developed test strips. The operation was determined according to the method described above. These samples were also examined by the agar diffusion test and PCR test, to compare and analyze the results of these tests with those obtained via ICG strip test.

\section{RESULTS}

\section{Optimal Concentration of the Coating Antibody and Capture Antibody}

Concentrated virus suspension was confirmed positive for PCR test. The concentration of GPV suspension was determined to be $1.2 \mathrm{mg} / \mathrm{ml}$ and the purity is above $85 \%$, which both verified by SDS-PAGE and analyzed by Quantity One software. Hybridomas were obtained by the fusion of spleen cells from immunized mice with SP2/0 myeloma cells as described above. The results

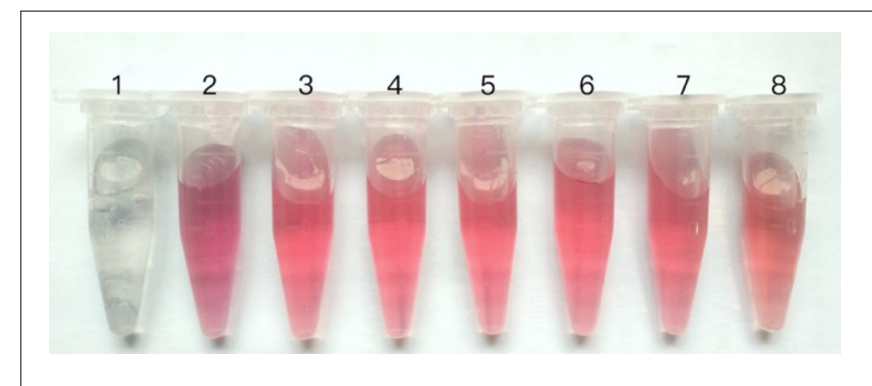

FIGURE 2 | The illustration of immunochromatographic test results.

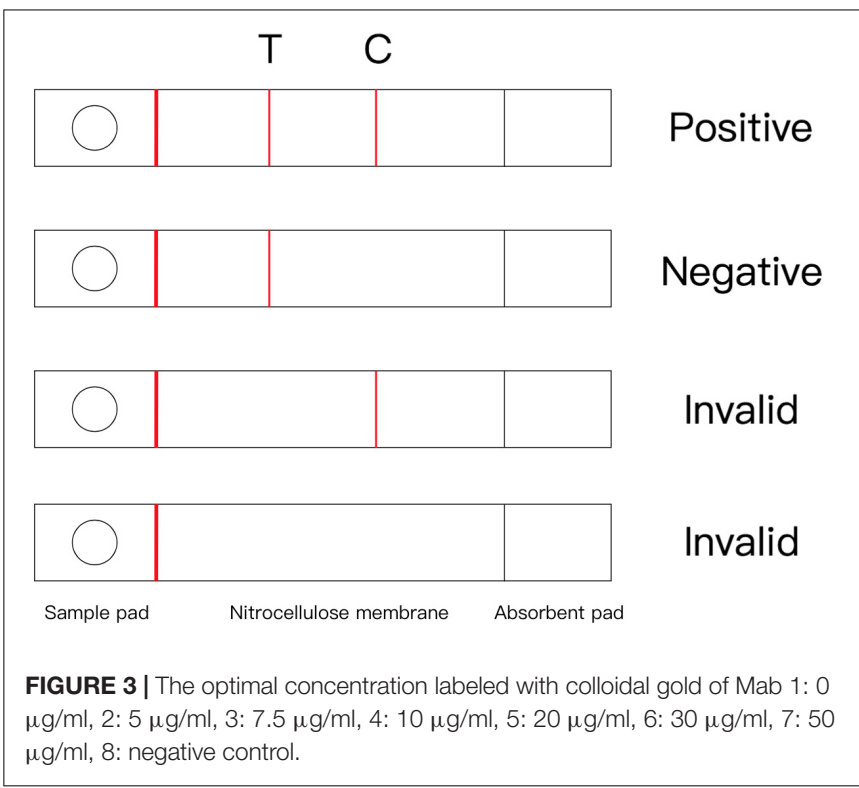


of affinity purification for the selected clones displayed high affinity and no cross-reactivity with related virus molecules. The monoclonal antibody was purified by sequential precipitation and determined to be $5 \mathrm{mg} / \mathrm{ml}$ with the DeNovix equipment. For the capture antibody, the minimum Mab concentration labeled with colloidal gold of red invariant is $7.5 \mu \mathrm{g} / \mathrm{ml}$ (Figure 2), therefore optimal concentration was determined to be $9 \mu \mathrm{g} / \mathrm{ml}$ according to the methods in Section "Materials and Methods."

After four immunizations for 5 weeks, the antibody titers in the serum reached 1:256. The polyclonal antibody was purified by sequential precipitation was determined to be $3.2 \mathrm{mg} / \mathrm{ml}$ with Bradford method. The purified pAb was diluted into gradient concentration, and the color of the test line deepened gradually as the concentration of pAb increased. When the concentration of $\mathrm{pAb}$ reached $1.6 \mathrm{mg} / \mathrm{ml}$, the color of the test line was maintained. Therefore, the optimal concentration of the coating antibody is $1.6 \mathrm{mg} / \mathrm{ml}$.

\section{Result Verdict and Effectiveness of the Immunochromatographic Strip}

In this assay, 80-120 $\mu$ l of samples were added to the sample pad of the immunochromatographic strip, then the strip flat for 5$7 \mathrm{~min}$. As described in Figure 3, if the sample contained GPV, the red band appears at the $\mathrm{T}$ line and the $\mathrm{C}$ line; if the GPV is not present in the sample, the red band appears only at the $\mathrm{C}$ line. When there is no red band at the $\mathrm{Cline}$, the test results are invalid

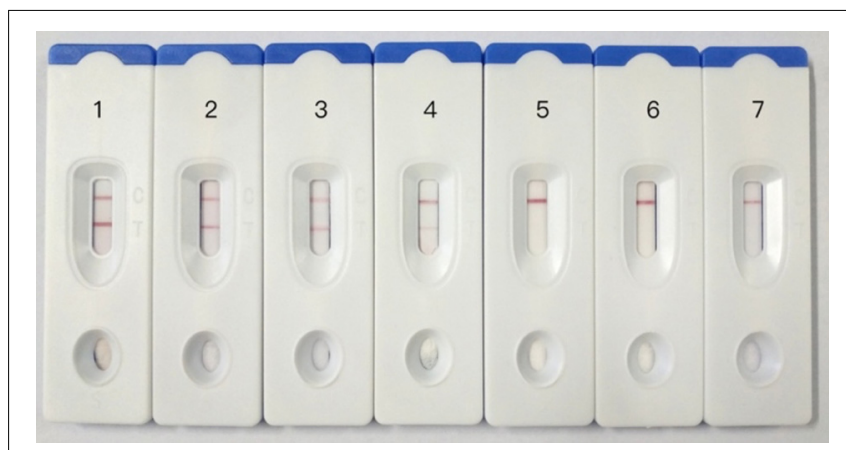

FIGURE 4 | Sensitivity testing of immunochromatographic strip. 1: GPV, 1.2 $\mathrm{mg} / \mathrm{ml}, 2:$ GPV, $120 \mu \mathrm{g} / \mathrm{ml}, 3:$ GPV, $12 \mu \mathrm{g} / \mathrm{ml}, 4:$ GPV, $1.2 \mu \mathrm{g} / \mathrm{ml}, 5:$ GPV, 120 ng/ml, 6: GPV, 12 ng/ml, 7: GPV, 1.2 ng/ml.

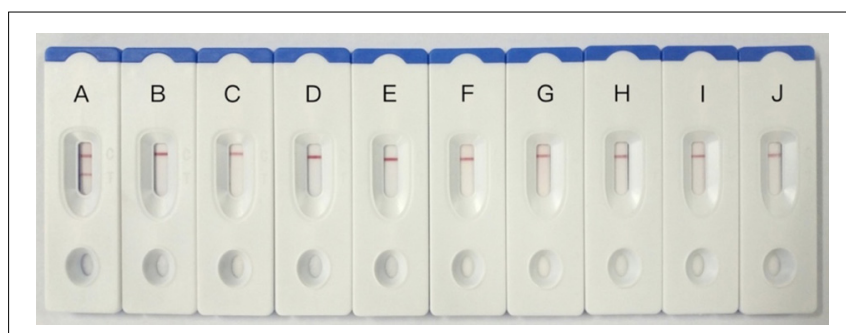

FIGURE 5 | Specificity testing of immunochromatographic strip. (A) Goose parvovirus, (B-D) avian influenza virus (H5, H7, H9), (E) duck hepatitis virus, (F) tembusu virus, (G) fowl adenovirus, (H) goose reovirus, (I) muscovy duck parvovirus, (J) negative control. regardless of whether the red band appears at the $\mathrm{T}$ line (Shim et al., 2013).

A panel of control biological samples (positive and negative control for GPV) were examined by ICG strip. The result showed that both two red band appeared when examining the positive control and one red band appeared only at the $\mathrm{C}$ line when examining the negative control.

\section{Sensitivity of the Immunochromatographic Strip}

The sensitivity of the ICG assay was evaluated by testing 10 -fold serial dilutions of the virus concentration $(1.2 \mathrm{mg} / \mathrm{ml}$ to $1.2 \mathrm{ng} / \mathrm{ml}$ ), and the results showed in Figure 4 that the lowest limit of detection of the assay was $1.2 \mu \mathrm{g} / \mathrm{ml}$. By comparison, the result of agar diffusion test is $1.2 \mathrm{mg} / \mathrm{ml}$, and PCR test is $1.2 \mathrm{ng} / \mathrm{ml}$.

\section{Specificity of the Immunochromatographic Strip}

Goose parvovirus and other goose samples including avian influenza virus (H5, H7, H9), duck hepatitis virus, tembusu virus, fowl adenovirus, goose reovirus and muscovy duck parvovirus, were examined by the immunochromatographic strip, and results showed in Figure 5 that only GPV sample presented two red bands in test and control line and others presented only one red line in control line. These confirmed that the immunochromatographic strip had high specificity for detecting GPV, and no cross-reaction was observed.

\section{Stability of Immunochromatographic Strip}

To determine the stability of the immunochromatographic strip, the ICG assay was carried out with the same batch of strips after stored at $4^{\circ} \mathrm{C}$ and $25^{\circ} \mathrm{C}$ for 8 months. The results have been

TABLE 1 | Stability experiment results.

\begin{tabular}{lccccccccc}
\hline $\begin{array}{l}\text { Storage } \\
\text { temperature }\end{array}$ & \multicolumn{7}{c}{ Storage time (month) } \\
\cline { 2 - 10 } & $\mathbf{1}$ & $\mathbf{2}$ & $\mathbf{3}$ & $\mathbf{4}$ & $\mathbf{5}$ & $\mathbf{6}$ & $\mathbf{7}$ & $\mathbf{8}$ \\
\hline $\begin{array}{l}\text { Room temperature } \\
\left(25^{\circ} \mathrm{C}\right)\end{array}$ & +++ & +++ & +++ & +++ & ++ & + & - & - \\
$\begin{array}{l}\text { Refrigerant } \\
\text { temperature }\left(4^{\circ} \mathrm{C}\right)\end{array}$ & +++ & +++ & +++ & +++ & +++ & +++ & + & - \\
\hline
\end{tabular}

+++ , the valid rate was $100 \%$; ++ , the valid rate was $66 \% ;+$, the valid rate was 33\%; - , the valid rate was $0 \%$.

TABLE 2 | Ninety-two clinical samples of suspected infected cases were used to detect the repeatability of this method.

\begin{tabular}{lrcc}
\hline Type of samples & \multicolumn{3}{c}{ Positive sample in the study } \\
\cline { 2 - 4 } & PCR test & Agar diffusion test & ICG strips test \\
\hline Goose allantoic fluid & $50 / 54$ & $2 / 54$ & $48 / 54$ \\
Supernatant of tissue & $37 / 38$ & $3 / 38$ & $32 / 38$
\end{tabular}


shown in Table 1, we can see that the ICG strip could be stored for 4 months at $25^{\circ} \mathrm{C}$ and for 6 months at $4^{\circ} \mathrm{C}$, respectively.

\section{Clinical Sample Application}

Immune colloidal gold strips test established in the study were performed on 92 clinical samples of suspected cases of GPV, and comparing the results of these tests with those obtained via agar diffusion test and PCR test. The results are summarized in Table 2. The positive rate of goose allantoic fluid was determined to be $88.8 \%$ by the ICG strips test and $92.6 \%$ by the PCR test, and the coincidence rate of these two methods was $96 \%$. For supernatants of tissue homogenate, it was $84.2 \%$ by the ICG strips test and $97.3 \%$ by the PCR test, and the coincidence was only $76.4 \%$. For all clinical samples, the coincidence rate was up to 91.9\%. Moreover, only few positive samples could be detected by agar diffusion test.

\section{DISCUSSION}

Thus far, China is already the largest country of waterfowl population in the world. However, infectious diseases are the biggest obstacle to the expansion and development of this industry, and GPV is one of the most serious viral pathogens. At present stage, prevention and early detection are still effective ways to control disease. Many routine detection methods for GPV had been developed. Specifically, GPV isolations using embryonating goose eggs, or primitive goose embryo fibroblasts are widely used in virology diagnosis. PCR have been effectively applied for the rapid detection since they were developed in the late 1990s. Real-time PCR test was used as a highly sensitive and specific method for quantitatively detecting GPV DNA, and thus can detect this virus. Furthermore, agar diffusion test and Loop-Mediated isothermal amplification were reported for more simple detection of GPV infections. Indirect ELISA based on VP3 protein are commonly used for the detection of GPV antibodies.

The colloidal gold-based immunochromatographic assay was considered to be a more rapid and simple detection method for pathogens in the field. It was widely applied in the specific detection of poultry and other pathogens, such as avian influenza virus, reovirus, mycoplasma suis. However, as we know, no research has yet to use this technique to detect GPV. So, in this study, a colloidal gold-based immunochromatographic assay was developed for the rapid detection of GPV. Compared with

\section{REFERENCES}

Fang, D. (1962). Recommendation of GPV. Vet. Sci. China 8, 19-20.

Ju, Y., Hao, H. J., Xiong, G. H., Geng, H. R., Zheng, Y. L., Wang, J., et al. (2010). Development of colloidal gold-based immunochromatographic assay for rapid detection of Streptococcus suis serotype 2. Vet. Immunol. Immunopathol. 133, 207-211. doi: 10.1016/j.vetimm.2009.08.010

Limn, C. K., Yamada, T., Nakamura, M., and Takehara, K. (1996). Detection of Goose parvovirus genome by polymerase chain reaction: distribution of Goose parvovirus in Muscovy ducklings. Virus Res. 42, 167-172. doi: 10.1016/01681702(95)01310-5

Liu, B., Wang, L., Tong, B., Zhang, Y., Sheng, W., Pan, M., et al. (2016). Development and comparison of immunochromatographic strips with previous ICG strip test, this method did not need to block NC membrane and conjugate pad in advance, but there was not a substantial drop-off of specificity and stability. In spite of the sensitivity of the assays developed is lower than that of PCR test, this method is more convenient, requires less equipment and can be completed within $10 \mathrm{~min}$. Furthermore, its sensitivity was significantly higher than that of agar diffusion test.

The results obtained with 92 clinical samples suspected of having GPV infection showed that positive incidence detected by the PCR test was similar with the ICG strip test. Particularly, the PCR test results of goose allantoic fluid were consistent with those of the ICG strip test in all except two cases. The result obtained from samples of supernatants of tissue homogenate was lower, which may be caused by the polyclonal antibody against GPV. In future research, we can develop another monoclonal antibody against GPV to apply as coating antibody.

\section{CONCLUSION}

It is very suitable for detection of GPV in the field by ICG strips test, and it has an important clinical significance for prevention and detection of pathogens.

\section{AUTHOR CONTRIBUTIONS}

YoD, YT, and XY conceived and designed the experiments. XY, $\mathrm{HC}, \mathrm{ZW}$, and YaD performed the experiments. XY, JY, and XN analyzed the data. XY and YT contributed reagents, materials, and analysis tools. XY and LW wrote the paper. LW promoted the product.

\section{FUNDING}

This work was supported by National Key Research and Development Program (2016YFD0500107); the National Natural Science Foundation of China (31272583 and 31472199); the China Agriculture Research System (CARS-43-10); Science and Technology Development Plan of Shandong Province (2014GNC111023); Major Agricultural Application Technology Innovation Project of Shandong Province in 2016; and Funds of Shandong "Double Tops" Program.

three nanomaterial labels: colloidal gold, nanogold-polyaniline-nanogold microspheres (GPGs) and colloidal carbon for visual detection of salbutamol. Biosens. Bioelectron. 85, 337-342. doi: 10.1016/j.bios.2016. 05.032

Liu, H., Xiu, Y., Xu, Y., Tang, M., Li, S., Gu, W., et al. (2017). Development of a colloidal gold immunochromatographic assay (GICA) for the rapid detection of Spiroplasma eriocheiris in commercially exploited crustaceans from China. J. Fish Dis. 40, 1839-1847. doi: 10.1111/jfd.12657

Liu, X., Xiang, J. J., Tang, Y., Zhang, X. L., Fu, Q. Q., Zou, J. H., et al. (2012). Colloidal gold nanoparticle probe-based immunochromatographic assay for the rapid detection of chromium ions in water and serum samples. Anal. Chim. Acta 745, 99-105. doi: 10.1016/j.aca.2012. 06.029 
Ma, H., Guo, J., Xia, J., Niu, C., Shen, X., Sun, H., et al. (2017). Preparation and application of rabbit anti-mouse Setd8 polyclonal antibody. Xi Bao Yu Fen Zi Mian Yi Xue Za Zhi 33, 246-251.

Meng, K., Sun, W., Zhao, P., Zhang, L., Cai, D., Cheng, Z., et al. (2014). Development of colloidal gold-based immunochromatographic assay for rapid detection of Mycoplasma suis in porcine plasma. Biosens. Bioelectron. 55, 396-399. doi: 10.1016/j.bios.2013.12.048

Paek, S. H., Lee, S. H., Cho, J. H., and Kim, Y. S. (2000). Development of rapid onestep immunochromatographic assay. Methods 22, 53-60. doi: 10.1006/meth. 2000.1036

Shao, H., Lv, Y., Ye, J., Qian, K., Jin, W., and Qin, A. (2014). Isolation of a Goose parvovirus from swan and its molecular characteristics. Acta Virol. 58, 194-198. doi: 10.4149/av_2014_02_194

Shim, W. B., Kim, J. S., Kim, M. G., and Chung, D. H. (2013). Rapid and sensitive immunochromatographic strip for on-site detection of sulfamethazine in meats and eggs. J. Food Sci. 78, M1575-M1581. doi: 10.1111/1750-3841.12232

Shukla, A. A., and Thommes, J. (2010). Recent advances in large-scale production of monoclonal antibodies and related proteins. Trends Biotechnol. 28, 253-261. doi: 10.1016/j.tibtech.2010.02.001

Yang, J., Yang, R., Cheng, A., Wang, M., Fu, L., Yang, S., et al. (2010). A simple and rapid method for detection of Goose parvovirus in the field by loop-mediated isothermal amplification. Virol. J. 7:14. doi: 10.1186/1743-42 2X-7-14

Yang, J. L., Cheng, A. C., Wang, M. S., Pan, K. C., Li, M., Guo, Y. F., et al. (2009). Development of a fluorescent quantitative real-time polymerase chain reaction assay for the detection of Goose parvovirus in vivo. Virol. J. 6:142. doi: 10.1186/1743-422X-6-142

Yin, W., Liu, J., Zhang, T., Li, W., Liu, W., Meng, M., et al. (2010). Preparation of monoclonal antibody for melamine and development of an indirect competitive ELISA for melamine detection in raw milk, milk powder, and animal feeds. J. Agric. Food Chem. 58, 8152-8157. doi: 10.1021/jf1006209

Zhang, L., Li, D., Liu, L., and Zhang, G. (2015). Rapid immunochromatographic test strip to detect swimming crab Portunus trituberculatus reovirus. Dis. Aquat. Organ. 117, 21-29. doi: 10.3354/dao02921

Zhang, Y., Li, Y., Liu, M., Zhang, D., Guo, D., Liu, C., et al. (2010). Development and evaluation of a VP3-ELISA for the detection of goose and Muscovy duck parvovirus antibodies. J. Virol. Methods 163, 405-409. doi: 10.1016/j.jviromet. 2009.11.002

Conflict of Interest Statement: The authors declare that the research was conducted in the absence of any commercial or financial relationships that could be construed as a potential conflict of interest.

Copyright (c) 2018 Yu, Wei, Chen, Niu, Dou, Yang, Wang, Tang and Diao. This is an open-access article distributed under the terms of the Creative Commons Attribution License (CC BY). The use, distribution or reproduction in other forums is permitted, provided the original author(s) and the copyright owner are credited and that the original publication in this journal is cited, in accordance with accepted academic practice. No use, distribution or reproduction is permitted which does not comply with these terms. 